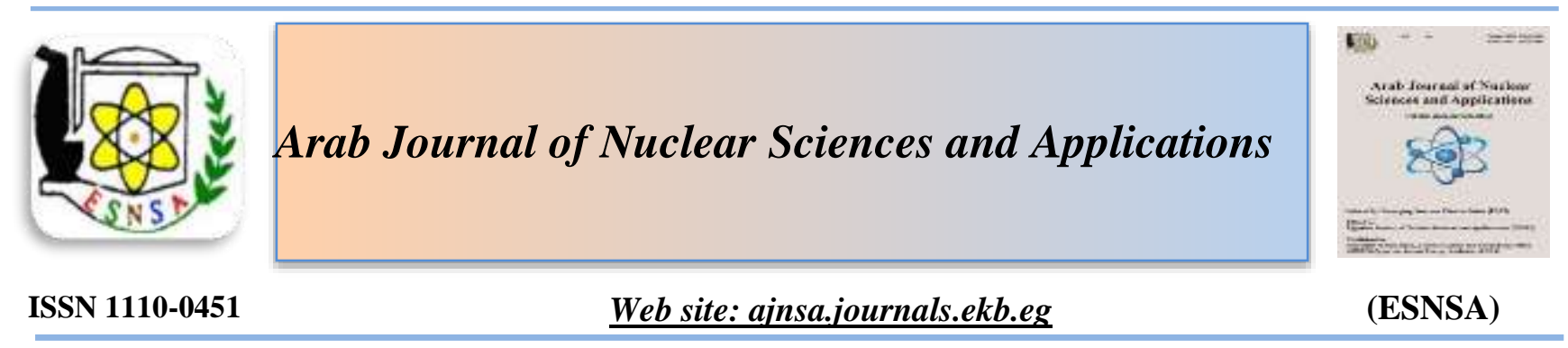

\title{
Preparation and Characterization of Chitosan-stabilized Selenium Nanoparticles for Ameliorating Experimentally Induced Diabetic Nephropathy in Rats
}

\author{
Safaa I. Khaterl, Saydat S. Abd-El Megid ${ }^{1}$, Alaa A. Ahmed ${ }^{1}$, S. I. Khater ${ }^{2,3}$, I. A. Ali ${ }^{3}$ \\ ${ }^{(1)}$ Faculty of Vet. Medicine, Zagazig University, Egypt \\ ${ }^{(2)}$ Radioactive Isotopes and Generators Department, Hot Labs. Center, Atomic Energy Authority, Egypt. \\ ${ }^{(3)}$ Cyclotron Project, Nuclear Physics Department, Nuclear Research Center, Atomic Energy Authority, Egypt
}

Chitosan-stabilized selenium nanoparticles (CTS-SeNPs) were prepared by the reduction technique. Accepted $11^{\text {th }}$ June 2020

Single phase structure of the SeNPs was confirmed using X-ray diffraction (XRD). Transmission Electron Microscope (TEM) showed that the particle size of the samples is in the range of $15 \mathrm{~nm}$. This experiment aimed to study the potentialeffect of (CTS-SeNPs) as a therapeutic factor in diabetic nephropathy in rats. Streptozotocin (STZ) was used to induce diabetes inrats; thirty-sixWistar rats were divided into three groups; control, STZ-induced diabetic, and STZ-induced diabetic rats treated withCTS-SeNPs groups at a dose $(2 \mathrm{mg} \mathrm{Se} / \mathrm{kg} / \mathrm{d})$. All groups were given respective treatment orally via a stomach tube for 2 months. The obtained data showed that,the diabetic group revealed the presence of Microalbuminurea, the indicator of diabetic nephropathy and showed a significant $(p<0.05)$ increase in fasting bloodglucose, urea, creatinine and MDA,it is significant that high expression level of TGF- $\beta 1$ and aldose reductase while the group treated with CTS-SeNPs revealed significant decline in all values compared to the diabetic group. The diabetic group showed a significant decrease in insulin level, total anti-oxidant capacity (TAC), GPx and SOD activity while, the treatedgroup showed a significant (p < 0.05) increase in these values compared to the diabetic group. Kidney tissue showed normal histological picture except for mild vascular and glomerular congestion in treated group when compared with the diabetic one. The present investigation suggests that CTS-SeNPs can moderate diabetic nephropathy in streptozotocin-induced diabetic rats.

\section{Introduction}

Keywords: Chitosan selenium nanoparticles, Diabetic, Nephropathy, oxidativestress
Diabetic Nephropathy (DN),one of the most complications of diabetes mellitus supposed to be a risk factor for vascular disease, and is usually between type 2 diabetes's peoples and is a main reason for the advancement of end stage renal disease (ESRD) in type 1 diabetes [1,2]. Approximately $20 \%$ to $40 \%$ of patients with type 1 or type 2 diabetes mellitus develop diabetic nephropathy [3]. SeNPs are considered a source of selenium that provides optimum in vivo bioavailability with a decreaseof the risk of selenium toxicity. The biocompatibility and degradability of SeNPs in vivo are significantly preferable than noble metals as silver, gold and platinum. In addition, when compared to organic and inorganic forms of selenium, Se in many nanoforms has appeared lower toxicity and superior antioxidant and anti-tumor activity [4]. Besides, the anti-hyperglycemic activity of SeNPs has also been confirmed due to its antioxidant properties that can scavenge the free radicals generates due to hyperglycemia [5]. Chitosan(CTS), a natural polysaccharide is known to exhibit great bioactivities, such as antitumor, antibacterial, hypocholesterolemic, and antihypertensive activities, and the chitosan-

Corresponding author: sabkhater@yahoo.com

DOI: 10.21608/ajnsa.2020.19809.1300

(C) Scientific Information, Documentation and Publishing Office (SIDPO)-EAEA 
based nanoparticles exhibit high potency for treatment and prevention of diabetes and its complications, that is may be due to That CTS is a good stabilizer for nanoparticles.[6]. Due to the high antioxidant activity of chitosan (CS), the invitro antioxidant properties of selenite-loaded CS/TPP nanoparticles were significantly enhanced, compared with pure selenite [7]. The reason for conducting this study was to examine the possible application of CTS-SeNPs as a therapeutic agent in diabetic nephropathy in rats through determination of: serum blood glucose level, serum insulin level, kidney function test (Urea and Creatinine), serum total antioxidant capacity (TAC), Antioxidantactivities in Kidney homogenate; superoxide dismutase (SOD) and glutathione peroxidase (GPx), Malondialdehyde (MDA), Micro-albuminuria in urine sample \& studying the gene expression of transforming growth factor- $\beta 1$ (TGF- $\beta 1) \&$ Aldose reductasein the kidney tissueby using Real time polymerase chain reaction, and finally histopathological examination ofkidney tissue.

\section{Experimental}

Preparation of CTS-SeNPS

For preparing Se NPS, an aqueous solution of chitosan $(0.1 \%, 10 \mathrm{ml})$ was mixed with $80 \mathrm{ml}$ $(0.06 \mathrm{M})$ ascorbic acid under magnetic steering. 10 $\mathrm{ml}$ of $0.03 \mathrm{M}$ sodium selenite was added slowly to the mixture. The mixture was left under sonifiction condition for $5 \mathrm{~min}[8]$. The $\mathrm{pH}$ of solution controlled (5-6) by $\mathrm{NaOH}$. The solution was left in refrigerator for $24 \mathrm{~h}$. Se NPS were collected using centrifuge.

\section{Animals management}

Thirty six male adult Wistar rats 8 weeks age and weighing 200-220 gram were used in this study. The institutional animal Care and Use Committee of the Faculty of Veterinary Medicine, Zagazig University approved the presentstudy (ZUIACUC/2/F/91/2019). All animals were adapted for three weeks prior to the beginning of the study.

\section{Chemicals}

Streptozotocin (STZ) obtained from SigmaAldrich (Chemical Cp. St. Louis, Mo, USA). The STZ was mixed in freshly prepared sod.citrate buffer(pH of 4.5) then injected intraperitoneally for induction of T2DM [9].CTS-SeNPs were prepared by adjusted procedure [10].Nicotinamide was dissolved in normal saline and is usually administrated intraperitoneally [11].

CTS-SeNPs characterization, particle size and morphology:

The intended sample was characterized through Xray diffractometer (XRD). X-lab Shimadzu X6000 ), and identified with $\mathrm{Cu}-\mathrm{Ka}$ radiation. The particle size was determined using a HighResolution Transmission Electron Microscope (HR-TEM, Tecnai G20, FEI, Netherland).

\section{Induction of diabetes}

Whole night-fasted adult Wistar rats $(\mathrm{n}=36)$ were outfit type 2 diabetes viaa single dose of NicotinamideI/P (110 mg/kg BW) dissolved for 15 min in normal saline before injection of StreptozotocinI/P (65 mg/kg of BW) which dissolved in citrate buffer. Blood glucose levels were evaluated 2 days after STZ injection. Rats were evaluated diabetic when fasting blood glucose was $200 \mathrm{mg} / \mathrm{dl}$ or more [12].

\section{Animals grouping and dosing}

Thirty-six rats were obtained into three equal groups; control, STZ-induced diabeticand STZinduced diabetic rats groups treated withCTSSeNPs $(2 \mathrm{mg} \mathrm{Se} / \mathrm{kg} / \mathrm{d})$. for 8 weeks.

\section{Sampling}

The blood samples were obtained from orbital venous plexus then centrifuged and the top layer was used for determinationofbiochemical parameters[13].Immediately after scarifying, take kidney, weighted.Every sample was divided into 3 parts; one was wrapped in aluminum foil and put immediately in liquid nitrogen container to make snap-freezing for molecular investigation. The second part kept at $-20^{\circ} \mathrm{C}$ to be homogenized for antioxidants measurements. The last part kept in neutral buffered formalin $10 \%$ for histopathological analysis. The samplesof urine were obtained from urinary bladder for evaluation of microalbuminurea.

\section{Biochemical determinations:}

Serum glucose concentrations were assayed enzymatically using glucose commercial kit according to Trinder [14].Serum insulin concentrations were analyzed according to Ungeret al. [15].BUN was assayed by using Kit (Cat. No - 
5602-01) according to Marsh et al. [16].Creatinine was assayed using Kit (Cat. No- ab65340) according to Husdan and Rapoport [17].TAC was determined in serum using Total Antioxidant Capacity Assay Kit Cat. No- MAK187) according to Sies [18].Determination of GPx activity conferring to the procedure was described by Paglia and Valentine [19].Determination of SOD activity in kidney homogenate was evaluated accordingto the proceduregranted by Misra and Fridovich [20].Determination of MDA (Malondialdehvde)concentration was studied according to Esterbaueret al. [21].

\section{Molecular determinations:}

Determination of the levels of expression of (TGF$\beta 1$ and aldose reductase)was investigated using Real Time-PCR according to Ikeguchiet al. [22] and Maekawaet al. [23] usingPureLink ${ }^{\circledR}$ RNA Mini Kit obtained from Ambion by life technologies by Thermo Scientific, Catalog numbers: 12183018A and using the manufacture instructions. The formation of cDNA was done by using High Capacity cDNA Reverse Transcription Kit obtained from Thermo Scientific, code4374966. Amplification was done using SYBR Green qPCR Master Mix (2X) kit obtained from Thermo scientific, catalog \#K0251, to detect TGF$\beta 1$ and aldose reductase's expression. The amount of target gene expression levels was estimated using the formula of $2^{-\Delta \Delta \mathrm{ct}}[24]$ and using internal controlGAPDH. The primer sequences were designed by primer 3 program as fellow: aldose reductase primer,F3 'GGACCTCTACCTTATTCACTG-5 /R-3` TTGGCCCAGGGCCTGTCAG-5 TGF31primer,F-3 CTGAACCAAGGAGACGGAAT5`R-3`-GGTTCATGTCATGGATGGTG5 GAPDHprimer,F3`GGCACAGTCAAGGCTGA-GAATG-5 /R3ATGGTGGTGAAGACGCCAGTA-5

\section{Histopathological examination of Kidney:}

Sections from kidney were cut and stained byHematoxylin\& Eosin and examined microscopically according to Suvarnaet al. [25].

\section{Statistical analysis:}

The results were done using mean and standard error (Mean \pm SEM). ANOVA test has been done to test the significant changes among different groups. Duncan multiple range test was considered as a post hoc test. The statistical analysis was done using IBM SPSS version 25.

\section{RESULTS}

\section{CTS-SeNPs Charzterization}

For the X-ray diffraction analysis, the containing Se-NPs was dried as a powder and analyzed using a powder X-ray diffractometer. The peaks were noted to confirm the presence of Se-NPs. The instrument used for the analysis was X-lab Shimadzu X-6000), and identified with $\mathrm{Cu}-\mathrm{K} \alpha$ radiation.

\section{Particle size and Morphology}

The particle size was observed using a High Resolution Transmission Electron Microscope (HR-TEM, Tecnai G20, FEI, Netherland).

Effect of CTS-SeNPs (2 $\mathrm{mg} / \mathrm{kg} / \mathrm{b} . \mathrm{wt})$ in STZ induced diabetic rats on serum glucose and insulin levels

The diabetic group revealed a significant $(\mathrm{p}<$ 0.05) increase in blood glucose levelcompared with control group,while, the group treated with CTS-SeNPs showed a significant $(p<0.05)$ decrease in glucose level when compared to the diabetic one. Thediabetic group showed a significant $(\mathrm{p}<0.05)$ decrease in serum insulin level and the group treated with CTS-SeNPs showed a significant $(\mathrm{p}<0.05)$ increase in insulin level compared to the diabetic one. (table1).

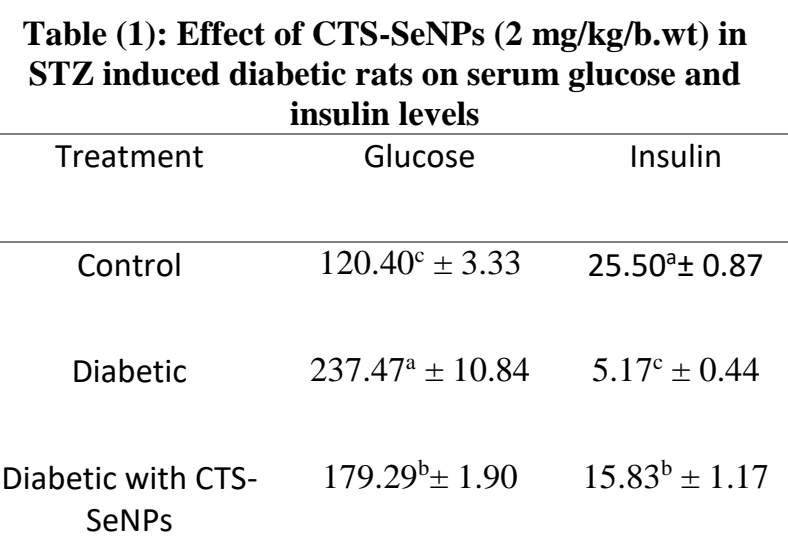

Values are represented as the mean \pm SE . The means within the same column carrying different superscripts $(\mathrm{a}, \mathrm{b}, \mathrm{c})$ are significant at $\mathrm{p}<0.05$. 
Effect of CTS-SeNPs (2 $\mathrm{mg} / \mathrm{kg} / \mathrm{b} . w \mathrm{t})$ in STZ induced diabetic rats onrenal injury biomarkers

In Table (2),showed that the diabetic group revealed a significant $(\mathrm{p}<0.05)$ elevation in the levels of kidney injury biomarkers (urea, creatinine and Microalbuminurea), while the treated group showed a significant $(\mathrm{p}<0.05)$ decrease in kidney injury biomarkers when compared to the diabetic group.

Effect of CTS-SeNPs (2 $\mathrm{mg} / \mathrm{kg} / \mathrm{b} . \mathrm{wt})$ in STZ induced diabetic rats on kidney oxidant/antioxidant status

Compared with the control group,the diabetic group revealed a significant $(\mathrm{p}<0.05)$ decrease in TAC, GPX \& SODlevel, while the treated group showed a significant $(\mathrm{p}<0.05)$ increase when compared to the diabetic group.Meanwhile, the treatment with CTS-SeNPs for 2 month resulted in a significant $(\mathrm{p}<0.05)$ decrease in lipid peroxidation marker MDA level when compared with the diabetic group.(table 3 ).

Effect of CTS-SeNPs (2 $\mathrm{mg} / \mathrm{kg} / \mathrm{b} . \mathrm{wt})$ in STZ induced diabetic rats on TGF- $\beta 1$ and Aldose reductase gene expression level

Table (4) showed that the diabetic group is significantly $(p<0.05)$ increased in the level of expression of TGF- $\beta 1 \&$ Aldose reductase compared with control group.while,the treatedgroup showed a significant $(\mathrm{p}<0.05)$ decrease in TGF- $\beta 1 \&$ Aldose reductase gene expression level when compared to the diabetic group.

Table (2): Effect of CTS-SeNPs (2 mg/kg/b.wt) in STZ induced diabetic rats on urea, creatinine and microalbuminurea levels

\begin{tabular}{cccc}
\hline Treatment & $\begin{array}{c}\text { Urea } \\
(\mathrm{mg} / \mathrm{dl})\end{array}$ & $\begin{array}{c}\text { Creatinine } \\
(\mathrm{mg} / \mathrm{dl})\end{array}$ & $\begin{array}{c}\text { Microalbuminurea } \\
(\mathrm{mg} / \mathrm{dl})\end{array}$ \\
\hline Control & $23.15^{\mathrm{c}} \pm 2.56$ & $0.56^{\mathrm{b}} \pm 0.0$ & $44.77^{\mathrm{c}} \pm 1.14$ \\
Diabetic & $63.51^{\mathrm{a}} \pm 3.90$ & $1.35^{\mathrm{a}} \pm 0.26$ & $100.93^{\mathrm{a}} \pm 1.39$ \\
Diabetic with CTS-SeNPs & $45.78^{\mathrm{b}} \pm 1.57$ & $0.62^{\mathrm{b}} \pm 0.03$ & $77.33^{\mathrm{b}} \pm 1.41$ \\
\hline
\end{tabular}

Values are represented as the mean \pm SE . The means within the same column carrying different superscripts (a, b, c) are significant at $\mathrm{p}<0.05$.

Table (3): Effect of CTS-SeNPs ( $2 \mathrm{mg} / \mathrm{kg} / \mathrm{b} . \mathrm{wt})$ in STZ induced diabetic rats on kidney oxidant/antioxidant status

\begin{tabular}{ccccc}
\hline Treatment & GPx $(\mathrm{ng} / \mathrm{mg})$ & SOD $(\mathrm{U} / \mathrm{mg})$ & MDA $(\mathrm{nmol} / \mathrm{ml})$ & TAC $(\mathrm{ng} / \mathrm{ml})$ \\
\hline Control & $34.75^{\mathrm{a}} \pm 1.01$ & $36.33^{\mathrm{a}} \pm 1.86$ & $29.55^{\mathrm{c}} \pm 1.62$ & $16.83^{\mathrm{a}} \pm 0.60$ \\
Diabetic & $13.00^{\mathrm{c}} \pm 0.38$ & $8.42^{\mathrm{c}} \pm 1.86$ & $124.67^{\mathrm{a}} \pm 3.18$ & $3.83^{\mathrm{c}} \pm 0.60$ \\
Diabetic with CTS-SeNPs & $24.58^{\mathrm{b}} \pm 0.96$ & $26.33^{\mathrm{b}} \pm 0.93$ & $64.00^{\mathrm{b}} \pm 3.21$ & $12.17^{\mathrm{b}} \pm 0.94$ \\
\hline
\end{tabular}

Values are represented as the mean \pm SE . The means within the same column carrying different superscripts (a, b, c) are significant at $\mathrm{p}<0.05$. 
Histopathological results

Thecontrol rat showed normal histological structure (Fig.1A). The STZ-induced diabetic rats, kidney showed marked epithelial necrosis, vascular congestion, cast formation, severe hemorrhages and vascular congestion (Fig 1B). The STZ-induced diabetic rats administered CTSSeNPs kidney showed mild cast formation and regenerative epithelium, Fig (1C).

\section{Discussion}

Fig (2) shows the XRD pattern for Se NPs. The XRD pattern for the Se-NPs shows diffraction peaks at $2 \theta$ (degrees) of $23.68^{\circ}, 29.84^{\circ}, 41.4^{\circ}$, $43.74^{\circ}, 45.56^{\circ}, 51.88^{\circ}, 56.34^{\circ}, 61.78^{\circ}, 65.34^{\circ}$ and $71.68^{\circ}$ which correspond to the (100), (101), (110), (102), (111), (201), (112), (202), (210) and (113) planes of the Se-NPs. All the diffraction peaks in the $2 \theta$ range correspond to the hexagonal structure of selenium. The lattice parameters ( $a$ and $c$ )were calculated according to the equation, $\frac{1}{a^{2}}=$ $\frac{4}{3}\left(\frac{h^{2}+h k+k^{2}}{a^{2}}\right)+\frac{l^{2}}{c^{2}}$, where $\mathrm{h}, 1$, and $\mathrm{k}$ are miller indices. The calculated lattice parameters values are $a=4.337 \AA$ and $c=5.631 \AA$ and have an agreement with the results were obtained by [25]. The crystallite size D of the Se-NPs has been calculated using Debye-Scherrer's equation: $\mathrm{D}=$ $0.94 \lambda /(\beta \cos \theta)$ where $\lambda$ is the wavelength of the $X-$ ray radiation, $\beta$ is the full width at half maximum and $\theta$ is the angle of diffraction. The crystallite size of the Se-NPs recorded $21.47 \mathrm{~nm}$. There is a deviation from the results from the DebyeScherrer's Eq. from the results from the TEM images. This is because of Debye-Scherrer's constant 0.89 or 0.9 for $(\beta)$ was taken as spherical crystals with cubic unit cells. [26].

Table (4):Effect of CTS-SeNPs ( $2 \mathrm{mg} / \mathrm{kg} / \mathrm{b} . w \mathrm{w})$ in STZ induced diabetic rats on TGF- $\beta 1$ and Aldose reductase gene expression level

\begin{tabular}{ccc}
\hline Treatment & TGF- $\beta 1$ & Aldose reductase \\
\hline Control & $1.00^{\mathrm{c}} \pm 0.27$ & $1.00^{\mathrm{c}} \pm 0.22$ \\
Diabetic & $3.48^{\mathrm{a}} \pm 0.23$ & $3.66^{\mathrm{a}} \pm 0.24$ \\
Diabetic with CTS-SeNPs & $1.86^{\mathrm{b}} \pm 0.38$ & $2.20^{\mathrm{b}} \pm 0.24$ \\
\hline
\end{tabular}

Values are represented as the mean \pm SE . The means within the same column carrying different superscripts (a, b, c) are significant at $\mathrm{p}<0.05$.
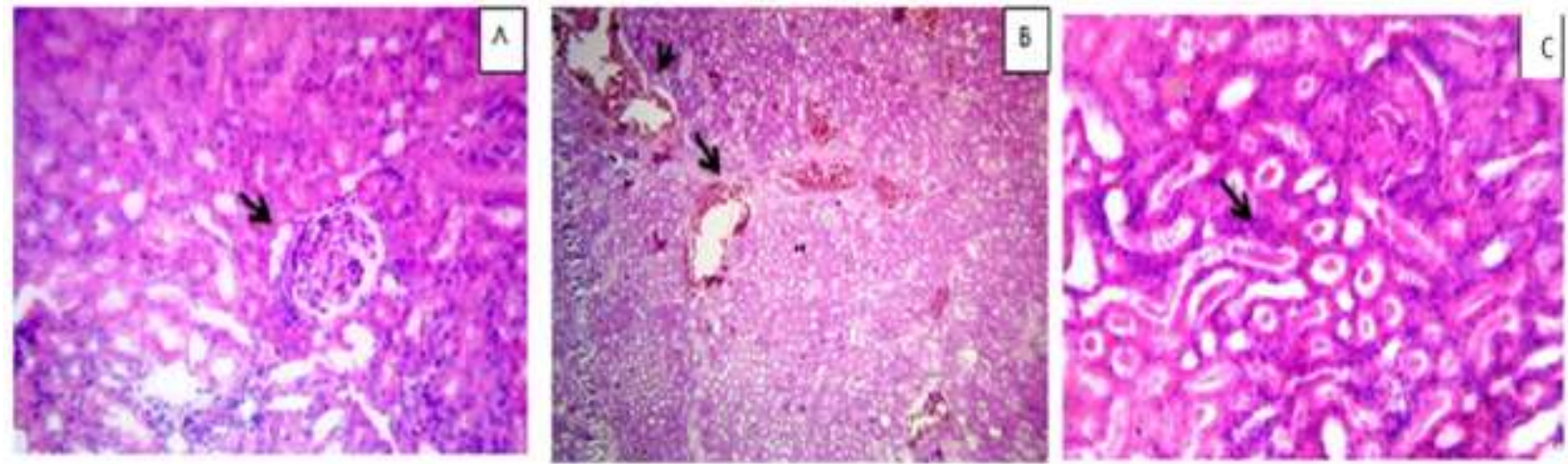

Fig. (1): Histopathological results on kidney revealed that A) Kidney of control rat showing normal histological structure, H\&E, X 400. B) Kidney of rat showing severe hemorrhages and vascular congestion, H\&E, X 400 . C) Kidney of rat showing mild cast formation and regenerative epithelium, H\&E, X 400. 


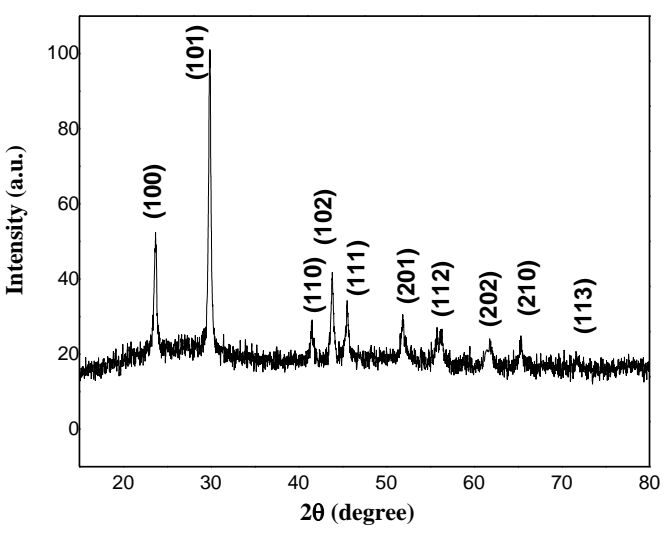

Fig. (2):XRD pattern for Se NPs

TEM analysis is an important technique that gives information about the shape and average particle size of the NPs. The particle size of the prepared Se NPs is shown in Fig (3). From the TEM micrographs, the particle size is nearly around 15 $\mathrm{nm}$.

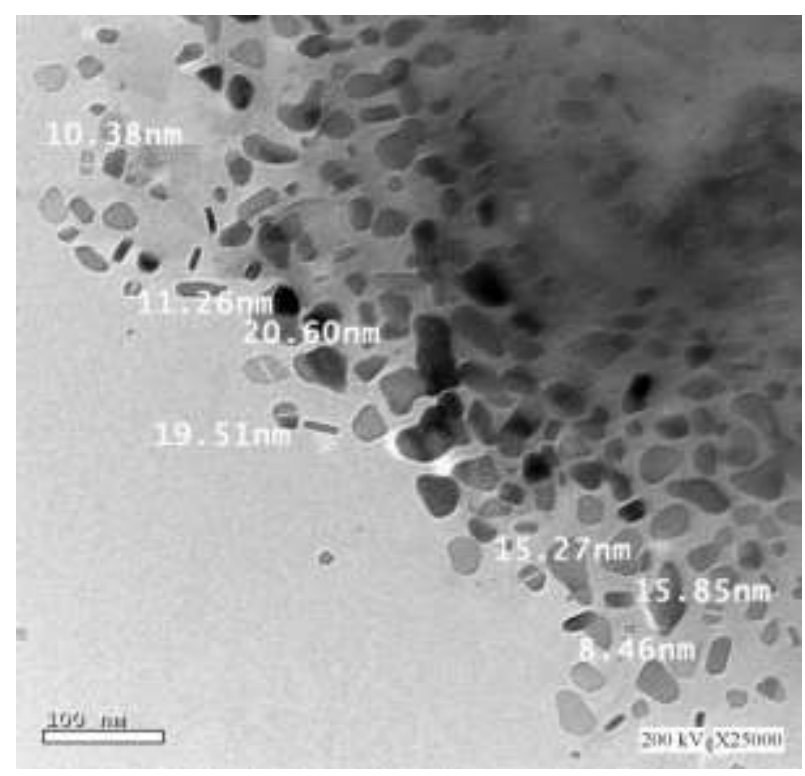

Fig. (3): TEM images and particles size for the Se NPs

Diabetic Nephropathy (DN) is one of the prime microvascular complexities of T2DM and is the primary cause of ESRD that cause premature death in diabetic patients all over the world. [27].Hyperglycemia cause oxidative stress: hyperglycemia activates the polyols pathway, which over-use NADPH and increase the production of superoxide anions. The autooxidation of glucose, and nonenzymatic glycosylation of proteins, generate free radicals. The free radicals are the main initiators of lipid peroxidation, a chain reaction that generates more and more lipoperoxides free radicals which lead to alteration of DNA, redox sensitive proinflammatory genes may be activated, leading to cellular dis-functions. Thus oxidative stress is at the center of the pathogenic processes of diabetic complications [27].

Our findings were reinforced by those of AlQuraishy et al. [28]who demonstrated that insulin`s elevation in diabetic rats, once they are treated with SeNPs and/or insulin results in improved glycemic controlalso[29] approved that the levels of fasting blood sugar in all groups treated with selenium nanoparticles had a significant reduction compared to the diabetic group.

In our study, elevated levels of serum urea and creatinine were observed in untreated diabetic rats, which considered as the hallmark for renal dysfunction and declined with the treated group and this agreed with another study[30], who approved thatdiabetes leads to kidney dysfunction and stimulatesrenal injury biomarkers (uric acid, urea and creatinine) .The treatment of diabetic rats with selenium nanoparticles improved and declined the increased level of urea and creatinine [28]which is approved with the results of this study. SeNPs may have a reducing effect on serum levels of kidney factors such as albumin, urea and creatinine in diabetes.

Due to elevation in the reactivity of particles as a result of the increased ratio of surface area to volume and consequently, a gradual reduction in particle sizes, applying selenium nanoparticles comparing with selenium itself, which leads to quicker and more efficient effects on kidney functions in diabetes [31].We also investigated the level of microalbuminuria in the urine sample and the results showed that the diabetic group had a significantincrease in Microalbuminurea and the group treated with CTS-SeNPs showed a significant decrease in Microalbuminurea compared to the diabetic group. DN is defined as microalbuminuria that is, a Urinary Albumin 
Excretion of $\geq 300 \mathrm{mg}$ in a 24 hour collection or macroalbuminuria and abnormal renal function [32].

The generation of ROS due to hyperglycemia leads to apoptosis and renal damage, further leading to diabetic microvascular complications. So, it clearsnecessary to explore clinical therapies against oxidative stress as additional standard treatments for diabetic patients [29].

Ansaret al. [33]investigated that Se pretreatment increase TAC levels significantly compared to the AgNP group. The Se and SeNPs administration effects lead to antioxidative and protective effects evidenced by the increase of TAC and reduction in MDA contents. and this findings comes beside our results.

Eidet al. [34]investigated that nano-Se supplementation upregulated activities of SOD, GPx, GSH in serum and liver tissue of growing rabbits, as well as liver TAC. It also down regulated $(\mathrm{P}<0.01)$ serum GSSG, NO levels and MDA and $8-\mathrm{OHdG}$ in liver tissue. In one line, nano-Se inducedplasma GPx, SOD, TAC and declined MDA of non-stressed rats more than in control.GPX catalyzes the reduction of lipid peroxides into corresponding alcohols and free hydrogen peroxide into water via reduced glutathione. This function of GPx is significantly important in antioxidant defense and in maintenance of the health of cells and organisms.

Selenium can improve diabetes viacollaboratingin GPx1. GPx-1 is effective in the protection of pancreatic beta cells against the damage which caused by STZ. The study of selenium effects on diabetic-induced rats has shown that the treatment with selenium causes recovery and restoration of endothelial dysfunction and vascular disorders through regulating antioxidant enzymes and releasing nitric oxide[35]. SeNPs is known to have antioxidant effects. This leads to increase activities of both GPX and glutathione S-transfers leading to less oxidative stress [36].Nafiuand and Rahman, [37] documented the impact of $\mathrm{Se}^{2+}$ or $\mathrm{Zn}^{2+}$ added papaya extracts in vivo excision wound model. $\mathrm{Se}^{2+}$ added to papaya extract induces expression of TGF- $\beta$ and VEGFA for wound repair. Fu et al. [38] explained that VEGFA and TGF- $\beta$ play a part in the natural cutaneous wound healing by attracting inflammatory cells, cellular proliferation, neovascularization and epithelial migration.

Another study explained that Se deficiency causes increased oxidative stress via TGF-1 in normal and STZ diabetic rats. Results indicated that $\mathrm{Se}$ deficiency led to renal oxidative stress and renal injury via TGF-1 [39] andthese findings agreed with our study.

Inhibition of aldose reductase (AR), the main enzyme in polyl pathway lead toa decline in the expression of some inflammatory markers in the heart and aorta, and IL-1 $\beta$ in the serum of STZ induced diabetic mice [40].

In silico-studies of eleven ligands explained that the glycoalkaloids (vicine) possessed good glide score against the receptor aldose reductase comparable with that of a standard drug metformin for Type-2 diabetes mellitus`streatment [41].Asadiet al. [42] documented the induction of diabetes induced glomerular hyperfiltrationdue to the structural changes as cell growth, mesangial expansion, and glomerular basement membrane thickening [423]. This finding in agreementwith previous researches since the presence of glomerular hyperfiltration in incipient DN having previously been reported in both clinical trials and animal models [44].Sections from untreated diabetic kidney showed several glomerular and tubuleinterstitial changes as compared to control. Observed lesions as dilated tubules with thickening of the basement membrane of glomeruli [45] and this agreed with our histopathological finding.

\section{Conclusion}

These findings suggest that CTS-SeNPs possess a potential effectin preventing diabetic nephropathy via improving oxidative stress and kidney functions. Future investigations regarding CTSSeNPs in the prevention of development and progression of diabetic nephropathy introduce the hope for use of lower doses or in combination with other hypoglycemics which add to the safety and efficacy of both drugs. However, future studies are needed to understand the hypoglycemic activity of SeNPs and/or the possible toxicity increases after SeNPs are administered for a long time before starting any clinical trials. 


\section{Disclosure statement}

The authors declare no conflicts of interest, financial or otherwise.

\section{References}

1-Kumar, S.; Singh, R., Vasudeva, N., Sharma, S. (2012): Acute and chronic animal models for theevaluation of anti-diabetic agents. Cardio vasc Diabetol. 11:9.

2-Saran, R., Li, Y.; Robinson, B., Abbott, K.C., Agodoa, L.Y.C., Ayanian, J.; Bragg-Gresham, J.; et al. (2016):US renal data system 2015 annual data report: Epidemiology of kidney disease in the United States. AJKD J. 67(3): A7-A8.

3-Frederik, P.Peter, R.(2017): Diagnosis of diabetic kidney disease: state of the art and future perspective. Kidney international journalsupplements,8(1), 2-7.

4-Chaudhary, S., Umar, A., Mehta, S.K. (2014): Surface Functionalized Selenium Nanoparticles for Biomedical Applications. Journal of BiomedicalNanotechnology.10(10):3004-3042.

5-Quraishy S.A., Dkhil M.A., Moneim A.E.A. (2015): Anti-hyperglycemic activity of selenium nanoparticles in stestreptozotocin-induced diabetic rats. Int. J. Nanomed., 10, 6741-6756.

6-Karadeniz,F. S Kim, K. (2014): Advances in Food and Nutrition Research, Vol. 73, Elsevier Chapter 3.

7-Luo Y.C., Zhang B.C., Cheng W.H. Wang Q. (2010), Preparation, characterization and evaluation of selenite-loaded chitosan/TPP nanoparticles with or without zein coating. Carbohydr. Polym., 82, 942-951.

8- T.F. Chen, Y.S. Wong, W.J. Zheng, Y. Bai, L. Huang, Selenium nanoparticles fabricated in Undaria pinnatifida polysaccharide solutions induce mitochondriamediated apoptosis in A375 human melanoma cells, Colloid Surf. B 67 26-31, (2008).

9-Akbarzadeh, A.; Norouzian, D.; Mehrabi, M.R.; Jamshidi, Sh.; Farhangi, A.; Allah, V.A.; Mofidian, S.M.A. Lame Rad, B. (2007): Induction of diabetes by Streptozotocin in rats. Indian $\mathrm{J}$ ClinBiochem. 22(2): 60-64.

10-Chen, T.F., Wong, Y.S., Zheng, W.J., Bai, Y. Huang, L. (2008): Selenium nanoparticles fabricated in Undariapinnatifida polysaccharide solutions induce mitochondria-mediated apoptosis in A375 human melanoma cells. Colloid Surf.B. 67.

11-Badole, S.L., Jangam, G.B., Chaudhari, S.M., Ghule, A.E. ,Zanwar, A.A. (2014): L-glutamine supplementation prevents the development of experimental diabetic cardiomyopathy in streptozotocin-nicotinamide induced diabetic rats. PLoS One. 9(3): e92697.

12-Badr, G., Mahmoud, M., Badr, B. ,Mohany, M. (2012): Treatment of diabetic mice with undenatured whey protein accelerates the wound healing process by enhancing the expression of MIP-1 $\alpha$, MIP-2, KC, CX3CL1 and TGF- $\beta$ in wounded tissue. BMC Immunology. 13(1):32.

13-Parasuraman, S., Raveendran, R. ,Kesavan, R. (2010): Blood sample collection in small laboratory animals. Journal of pharmacology \&pharmacotherapeutics. 1(2):87.

14-Trinder, P. (1969): Determination of glucose in blood using glucose oxidase with an alternative oxygen acceptor. Annual of clinical biochemistry.6:24-30.

15-Unger, R.H., Eisentraut, A.M., McCall, M.S. ,Madison, L.L. (1961): Glucagon antibodies and an immunoassay for glucagon. J. Clin. Invest. 40:1280.

16-Marsh, W. H.; Fingerhut, B.,Miller, H. (1965): Automated and manual direct methods for the determination of blood urea. Clinical chemistry, 11(6), 624-627.

17-Husdan, H., Rapoport, A. (1968): Estimation of creatinine by the jaffe reaction a comparison of three methods. Clinical Chemistry. 14(3), 222-238.

18-Sies, H. (1997): Oxidative stress: oxidants and antioxidants. Experimental Physiology. 82 (2): 291 295.

19-Paglia, D.E., Valentine, W.N. (1967): Studies on the quantitative and qualitative characterization of erythrocyte glutathione peroxidase. Lab Clin Med. 70:158-169.

20-Misra, H.P. , Fridovich, I. (1972): The role of superoxide anion in the autoxidation of epinephrine and a simple assay for superoxide dismutase. J. Biol. Chem. 247: 3170.

21-Esterbauer, H., Cheeseman, K.H., Dianzani, M.U., Poli, G. , Slater, T.F. (1982): Separation and characterization of the aldehydic products of lipid peroxidation stimulated by $\mathrm{ADP}-\mathrm{Fe}^{2+}$ in rat liver microsomes. Biochem Journal. 208:129-140.

22-keguchi, M,., Iwamoto, A,., Taniguchi, K,., Katano, K. , Hirooka, Y. (2005):The gene expression level of transforming growth factor-beta (TGF-beta) as a biological prognostic marker of hepatocellular carcinoma. J Exp Clin Cancer Res. 24, 415-21.

23-Maekawa, K,., Tanimoto, T,., Okada, S., Suzuki, T. (2001):Expression of aldose reductase and sorbitol dehydrogenase genes in Schwann cells isolated from rat: Effects of high glucose and osmotic stress. Molecular Brain Research. 87(2):251-6.

24-Livak, K.J., Schmittgen, T.D. (2001): Analysis of relative gene expression data using real-time quantitative PCR and the 2(-Delta Delta C (T)) Method. Methods, 25(4), 402- 408.

25-Suvarna, S.K., Layton, C.,Bancroft, J.D. (2013): Bancroft theory and practice of Histological Techniques. 7th ED., Churchill Livingstone. Elsevier, England.

26-Ahmad Monshi, Mohammad Reza Foroughi, Mohammad Reza Monshi (2012): Modified Scherrer 
Equation to Estimate More Accurately, NanoCrystallite Size Using XRD World J. Nano Sci. and Eng., (2): 154-160.

27-Kasetti, R.B., Rajasekhar, M.D., Kondeti, V.K., (2010): Antihyperglycemic and antihyperlipidemic activities of methanol:water (4:1) fraction isolated from aqueous extract of Syzygium alternifolium seeds in streptozotocin induced diabetic rats. Food Chem Toxicol. 48(4): 1078-1084.

28-Al-Quraishy, S., Dkhil, M.A., Abdel Moneim, A.E. (2015): Anti-hyperglycemic activity of selenium nanoparticles in streptozotocin-induced diabetic rats. Int J Nanomedicine. 10: 6741-6756.

29-Mahnaz R.K., Ali G., Nasser N. A., Setare Z.D., Majid R., Saeed C.A., Azar R.Effects of selenium nanoparticles on kidney and liver functional disorders in streptozotocin-induced diabetic rats.Physiol Pharmacol 21 155-162.(2017).

30-Nabi, S.A., Kasetti, R.B.,Sirasanagandla, S.,Tilak, T.K.,Kumar, M.V. , Rao, C.A. (2013): Antidiabetic and antihyperlipidemic activity of Piper longum root aqueous extract in STZ induced diabetic rats. BMC Complement Altern Med. 13: 37.

31-Rezaei-Kelishadi, M., Ghasemi, A., Abdolyosefi, N., Zamani-Doabi, S.,(2017): Effects of selenium nanoparticles on kidney and liver functional disorders in streptozotocin-induced diabetic rats. PhysiolPharmacol 21 (2017): 155-162.

32-Whiting, D.R., Guariguata, L,., Weil, C. , Shaw, J. (2011):IDF diabetes atlas: global estimates of the prevalence of diabetes for 2011 and 2030. Diabetes Res ClinPract. 94(3):311-321.

33-Ansar, S., Alshehri, S.M., Abudawood, M., Hamed, S.S.,Ahamad, T. (2017): Antioxidant and hepatoprotective role of selenium against silver nanoparticles. International journal of nanomedicine, 12: 7789-7797.

34-Eid, S., Mustafa, E., Sayed, E.S., Farid, O., Ibrahim, M.M. (2019): Nano selenium treatment effects on thyroid hormones, immunity and antioxidant status in rabbits. World Rabbit Science.27: 93.

35-Oztürk, Z., Gurpinar, T., Vural, K., Boyacıoglu, S., Korkmaz, M.,Var, A. (2015): Effects of selenium on endothelial dysfunction and metabolic profile in low dose streptozotocin induced diabetic rats fed a high fat diet. Biotech Histochem. 90:506-515.

36-Peng D., Zhang, J., Liu, Q., Taylor, E.W. (2007): Size effect of elemental selenium nanoparticles (Nano-Se) at supranutritional levels on selenium accumulation and glutathione S-transferase activity. Journal of Inorganic Biochemistry. 101(10):14571463.

37-Nafiu, A., Rahman, M. (2015): Selenium added unripe carica papaya pulp extracts enhance wound repair through TGF- $\beta 1$ and VEGF-a signalling pathway. BMC Complementary and Alternative Medicine. 15.
38-Fu, X., Li, X., Cheng, B., Chen, W.,Sheng, Z. (2005): Engineered growth factors and cutaneous wound healing: success and possible questions in the past 10 years. Wound Repair Regen. 13:122-130.

39- Reddi, A., Bollineni, J.S. (2001): Seleniumdeficient diet induces renal oxidative stress and injury via TGF-1 in normal and diabetic rats. Kidney international. 59: 1342-53.

40- Pal, P., Sonowal, H., Shukla, K., Srivastava, S.,Ramana, K. (2017): Aldose Reductase Mediates NLRP3 Inflammasome- Initiated Innate Immune Response in Hyperglycemia-Induced Thp1 Monocytes and Male Mice. Endocrinology. 158.

41-Firdhouse, M.J., Lalitha, P. (2015): Maestro 9.4 as a Tool in the Structure Based Screening of Glycoalkaloids and Related Compounds, Targeting Aldose Reductase. Trends in Bioinformatics. 8(1): 26-36.

42-Asadi, S., Goodarzi, M.T., Karimi, J., Hashemnia, M., Khodadadi, I. (2019):Does curcumin or metformin attenuate oxidative stress and diabetic nephropathy in rats? J Nephropathol. 8(1): e8.

43-Bjornstad, P.;Cherney, D.Z., Maahs, D.M., Nadeau, K.J. (2016): Diabetic Kidney Disease in Adolescents With Type 2 Diabetes: New Insights and Potential Therapies. Current diabetes reports. 16(2):11.

44-Zhang, C., Meng, Y., Liu, Q., Xuan, M., Zhang, L., Deng, B., Injury to the endothelial surface layer induces glomerular hyperfiltration rats with earlystage diabetes. J Diabetes Res.[45] Akila, G., Djamil, K., Nawal, D, Saadia, B. (2018): Comparative study of antihypertensive and antioxidant effects of clove and metformin on renal dysfunction in streptozotocin-induced diabetic rats. PharmaNutrition, 6(1): 37-44. 